\title{
Management of Inflammatory Breast Cancers in Subsaharian Africa Context
}

\author{
Jean Marc Dia1 ${ }^{*}$, Lydie Estelle Djanhan², C. Saki1, Mouhideen Oyéladé1, Gérard Okon"1, \\ Abdoulaye Camara1, Abdoulaye Diallo1, Privat Guié1, Simplice Anongba1 \\ ${ }^{1}$ Department of Gynecology and Obstetrics, University Hospital of Treichville, Abidjan, Côte d'Ivoire \\ ${ }^{2}$ Department of Gynecology and Obstetrics, University Hospital of Bouaké, Bouake, Côte d'Ivoire \\ Email: *jmlaminedia@yahoo.fr
}

How to cite this paper: Dia, J.M., Djanhan, L.E., Saki, C., Oyéladé, M., Okon, G., Camara, A., Diallo, A., Guié, P. and Anongba, S. (2018) Management of Inflammatory Breast Cancers in Subsaharian Africa Context. Open Journal of Obstetrics and $G y$ necology, 8, 20-30.

https://doi.org/10.4236/ojog.2018.81003

Received: October 24, 2017

Accepted: January 2, 2018

Published: January 5, 2018

Copyright $\odot 2018$ by authors and Scientific Research Publishing Inc. This work is licensed under the Creative Commons Attribution International License (CC BY 4.0).

http://creativecommons.org/licenses/by/4.0/

\begin{abstract}
Objective: To report the experience of Gynecology Department of the University Hospital of Treichville in the management of the inflammatory breast cancers. Methodology: We conducted a retrospective and descriptive study on cases of the inflammatory breast cancers managed in the Gynecology Department of the University Hospital of Treichville, from January 2011 to December 2015. Results: We collected 44 cases of inflammatory breast cancer representing $17.9 \%$ of all breast cancers. The average age of patients was 46.5 years (32 - 70 years) and among them, the majority had inadequate socioeconomic level (90.9\%). The risk factor for cancer found in the majority of patients was the age of first menstrual periods before the age of 12 years $(52.3 \%)$. The average consultation time was long (10 months) and several patients had extensive inflammatory signs (38.6\%), with lymph node involvement (84.1\%) and metastases (36.4\%). At the histological analysis, the most common type was invasive ductal carcinoma (81.8\%), SBR grade III (54.5\%). Regarding treatment, mastectomy according to Patey associated with a chemotherapy was performed in $22.7 \%$ cases. The evolution has been marked by an overall 5 -year survival of $20 \%$. Conclusion: The management of inflammatory breast cancers was late and incomplete in our service making poor prognosis.
\end{abstract}

\section{Keywords}

Inflammatory Brest Cancers, Epidemiology, Diagnosis, Treatment

\section{Introduction}

Breast cancer, the first cancer of women in the world, is conventionally in a nodular form that is not identifiable to the inspection. In contrast, the inflammatory 
forms, called inflammatory breast cancers (IBC) are easily recognizable by the visualization of skin lesions of inflammatory type. Furthermore the IBC are worse prognosis than nodular forms, and must be considered immediately as metastatic cancers and treated as such [1].

Indeed the prognosis of inflammatory breast cancer is to be feared, with a median survival of 18 to 24 months in case of exclusive locoregional treatment. The use of chemotherapy, in particular neoadjuvant chemotherapy, combined with radiosurgical treatment, has improved the prognosis that is still reserved, with a 5-year recurrence-free survival between $30 \%$ and $50 \%$ [2].

In Western countries where IBC are uncommon, representing 3\% to $5 \%$ of breast cancers [2], their management is optimal thanks to an efficient technical equipment. But in our African countries, the technical equipment is limited making the management of IBC difficult. In these countries, there is also little publication on the management of IBC. We report through this study our experience in the management of IBC in our service with the objectives to describe the epidemiological, clinical, and therapeutic characteristics of patients.

\section{Methodology}

This is a retrospective and descriptive study conducted from $1^{\text {st }}$ January 2011 to $31^{\text {st }}$ December 2015 (5 years) in the gynecology department of the University Hospital of Treichville (CHUT), on patients managed for breast cancer.

Were included all the patients with inflammatory skin lesions of the breast with a histologic confirmation of invasive cancer.

The patients having inoperable cases were excluded from the study.

The parameters studied were the epidemiological, clinical, therapeutic characteristics and survivals. Survivals were evaluated from the date of diagnosis of certainty until the occurrence of death, by the Kaplan-Meier method.

Data were collected on a standardized survey form, from patient records, chemotherapy registers, operative report registers and phone calls.

Data analysis was done using Epi info version 7 software.

\section{Results}

\section{1) Epidemiological characteristics}

- Frequency

During the study period, breast cancer diagnosis was confirmed in 246 patients including 44 cases of IBC, a frequency of $17.9 \%$.

\section{- Socio-demographic characteristics}

The economic level of the patients was assessed according to their capacity to honor the various prescriptions made within the framework of the exploration and treatment report. Thus patients classified as low economic level were those who failed to meet more than $50 \%$ of prescriptions. Those who have honored between $50 \%$ and $80 \%$ have been classified as medium level and those who have honored more than $80 \%$ have been classified as high level (Table 1). 
The average age of the patients was 46.5 years ( 32 - 70 years) and among them, $61.3 \%$ were under 50 years.

In addition, $81.8 \%$ of patients had an insufficient level of education (not educated or primary) and $90.9 \%$ insufficient economic level (low or medium)

\section{- History}

The risk factor for cancer found in the majority of patients was the age of first menstrual periods before the age of 12 years (52.3) (Table 2).

\section{2) Tumor characteristics}

\section{- Clinical characteristics}

The average delay between the first signs and first consultation was 10 months (extreme: 1 month - 36 months) and 22 patients (50\%) consulted within the 6 months following the first signs (Table 3 ).

\section{- Histological characteristics}

Only 19 patients have performed immunohistochemistry which helped determine the Ki 67, the hormonal receptor status (HR) and HER2 (Table 4).

3) Carcinological treatments performed (Table 5)

- 10 patients underwent a mastectomy (according Patey) with axillary removal, associated with a neoadjuvant chemotherapy, then adjuvant

- 9 patients with metastases underwent a palliative chemotherapy

- 19 patients have the benefit of an additional targeted therapy with surgery and chemotherapy

\section{4) The survival}

\section{- Global survival}

The overall survival at 5 years was $20 \%$ with 19 deaths.

\section{- Survival according the treatment}

Table 1. Distribution of patients according to their socio-demographic characteristics.

\begin{tabular}{|c|c|c|}
\hline Socio-demographic characteristics & Population & Frequency (\%) \\
\hline \multicolumn{3}{|l|}{ Age (years) } \\
\hline$-\quad<40$ & 13 & 29.5 \\
\hline$-40-49$ & 14 & 31.8 \\
\hline$-\quad 50-59$ & 15 & 34.1 \\
\hline$-\quad>60$ & 2 & 4.6 \\
\hline - Total & 44 & \\
\hline \multicolumn{3}{|l|}{ School education level } \\
\hline - Not educated & 11 & 25 \\
\hline - Primary & 25 & 56.8 \\
\hline - Secondary & 7 & 15.9 \\
\hline - Superior & 1 & 2.3 \\
\hline - Total & 44 & 100 \\
\hline \multicolumn{3}{|l|}{ Economic level } \\
\hline - Low & 23 & 52.3 \\
\hline - $\quad$ Medium & 17 & 38.6 \\
\hline - High & 4 & 9.1 \\
\hline - Total & 44 & 100 \\
\hline
\end{tabular}


Table 2. Distribution of patients according to their history.

\begin{tabular}{|c|c|c|c|}
\hline & History & population & Frequency (\%) \\
\hline \multicolumn{4}{|c|}{ Age of the first menstruation(years) } \\
\hline- & $<12$ & 23 & 52.3 \\
\hline- & $\geq 12$ & 21 & 47.7 \\
\hline- & Total & 44 & 100 \\
\hline \multicolumn{4}{|c|}{ Age of 1st childbirth (years) } \\
\hline- & Never & 1 & 2.3 \\
\hline- & $<30$ & 41 & 93.2 \\
\hline- & $\geq 30$ & 2 & 4.5 \\
\hline- & Total & 44 & 100 \\
\hline \multicolumn{4}{|l|}{ Parity } \\
\hline- & 0 & 1 & 2.4 \\
\hline- & $1-2$ & 13 & 11.4 \\
\hline- & $\geq 3$ & 30 & 68.2 \\
\hline- & Total & 44 & 100 \\
\hline \multicolumn{4}{|c|}{ Breastfeeding mode } \\
\hline- & Never & 5 & 11.4 \\
\hline- & Breastfeeding & 39 & 88.6 \\
\hline- & Total & 44 & 100 \\
\hline \multicolumn{4}{|c|}{ Hormonal contraception } \\
\hline- & No & 42 & 95.5 \\
\hline- & Yes & 2 & 4.5 \\
\hline- & Total & 44 & 100 \\
\hline \multicolumn{4}{|c|}{ Hormonal status } \\
\hline- & Menopaused & 16 & 36.4 \\
\hline- & Not menopausal & 28 & 63.6 \\
\hline- & Total & 44 & 100 \\
\hline \multicolumn{4}{|c|}{ History of benign breast disease } \\
\hline- & No & 42 & 95.5 \\
\hline- & Yes & 2 & 4.5 \\
\hline- & Total & 44 & 100 \\
\hline \multicolumn{4}{|c|}{ Family history of breast cancer } \\
\hline- & No & 41 & 93.2 \\
\hline- & Yes & 3 & 6.8 \\
\hline- & Total & 44 & 100 \\
\hline
\end{tabular}

The survival at 5 years was zero in untreated patients and $27 \%$ in patients who received for carcinological treatment.

\section{Discussion}

\section{1) Epidemiological characteristics}

\section{- Frequency}

In this series IBC (Figure 1, Figure 2) represented 17.9\% of all breast cancers, close to the rate found by N'Koua-Bon [3] in Congo (15.2\%). In North Africa and the developed countries, on the contrary, different authors report much lower rates, less than 10\% [4]-[9]. This higher frequency in our Sub-Saharan Africa could be explained by the fact that some non-inflammatory cancers diagnosed late at locally advanced stages can be taken for IBC. Indeed the diagnostic 
Table 3. Distribution according to clinical features.

\begin{tabular}{|c|c|c|c|}
\hline & Clinical characteristics & Population & Frequency (\%) \\
\hline \multicolumn{4}{|c|}{ Delay between first sign and first consultation (months) } \\
\hline- & $<3$ & 7 & 15.9 \\
\hline- & $4-6$ & 15 & 34.1 \\
\hline- & $7-12$ & 20 & 45.5 \\
\hline- & $>12$ & 2 & 4.5 \\
\hline- & Total & 44 & 100 \\
\hline \multicolumn{4}{|c|}{ Cancer localisation } \\
\hline- & Right breast & 23 & 52 \\
\hline- & Left breast & 21 & 48 \\
\hline- & Total & 44 & 100 \\
\hline \multicolumn{4}{|c|}{ Skin appearance } \\
\hline- & Limited inflammatory signs & 27 & 61.4 \\
\hline- & Extensive inflammatory signs & 17 & 38.6 \\
\hline- & Total & 44 & 100 \\
\hline \multicolumn{4}{|c|}{ Axillary lymphadenopathy } \\
\hline- & Yes & 37 & 84.1 \\
\hline- & No & 7 & 15.9 \\
\hline- & Total & 44 & 100 \\
\hline \multicolumn{4}{|l|}{ Metastases } \\
\hline- & Yes & 16 & 36.4 \\
\hline- & No & 28 & 63.6 \\
\hline- & Total & 44 & 100 \\
\hline
\end{tabular}

Table 4. Distribution according to the histological characteristics.

\begin{tabular}{lcc}
\hline HISTOTILOGICAL CHARACTERISTICS & POPULATION & FREQUENCY (\%) \\
\hline Histological type & 36 & 81.8 \\
IDC & 8 & 18.2 \\
ILC & 44 & 100 \\
Total & & \\
SBR Grade & 20 & 45.5 \\
II & 24 & 54.5 \\
III & 44 & 100 \\
Total & & \\
Lymph embol & 28 & 63.6 \\
Yes & 16 & 36.4 \\
No & 44 & 100 \\
Total & & \\
Hormonal receptors & 9 & $47.4 \%$ \\
Positive & 10 & $52.6 \%$ \\
Negative & 19 & 100 \\
Total & & \\
Ki 67 High $(>20 \%)$ & 11 & 57.9 \\
Intermediate $(10 \%-20 \%)$ & 6 & 31.6 \\
Low $(<10 \%)$ & 2 & 10.5 \\
Total & 19 & 100 \\
HER2 & 13 & 68.4 \\
Positive & 6 & 31.6 \\
Negative & 19 & 100 \\
Total & &
\end{tabular}

IDC: Infiltrating Ductal Carcinoma, ILC: Infiltrating lobular Carcinoma. 
Table 5. Distribution of patients according to the carcinological treatment performed.

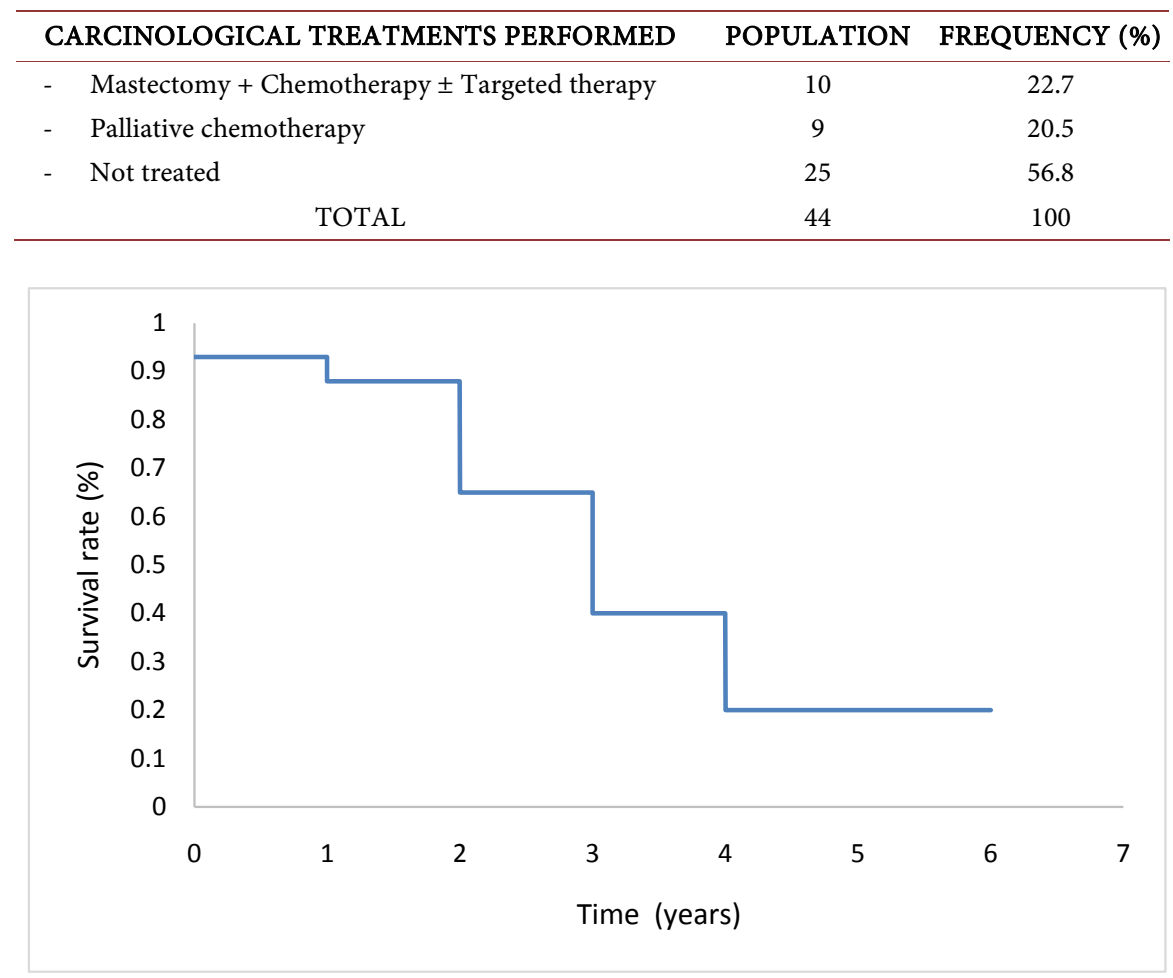

Figure 1. Survival curve in the overall population.

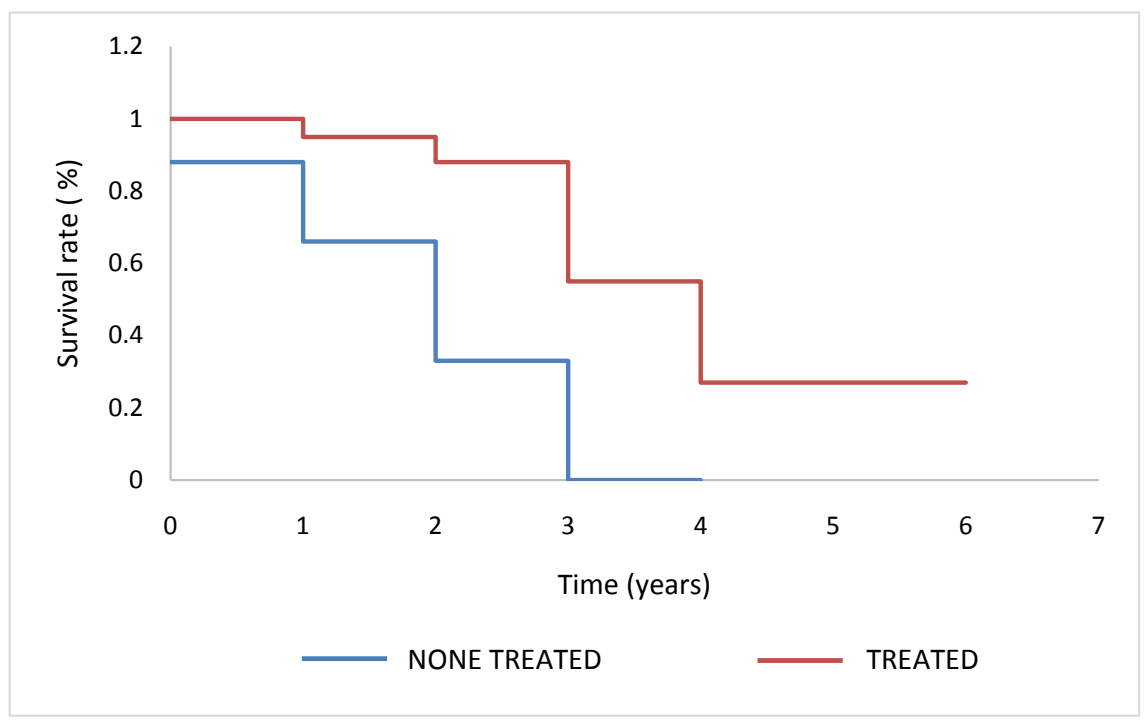

Figure 2. Survival curve according to the concept of treatment.

delays are common in our countries, confirmed in several studies [3] [10] [11]. And face to a breast cancer with inflammatory skin lesions (Figures 3-5), only "time" criterion permits to distinguish the IBC from locally advanced noninflammatory breast cancers. By definition in the IBC, inflammatory signs appear in less than six months [1]. However in our countries, insufficient educational level of some patients does not allow them to specify the exact duration of disease progression. 


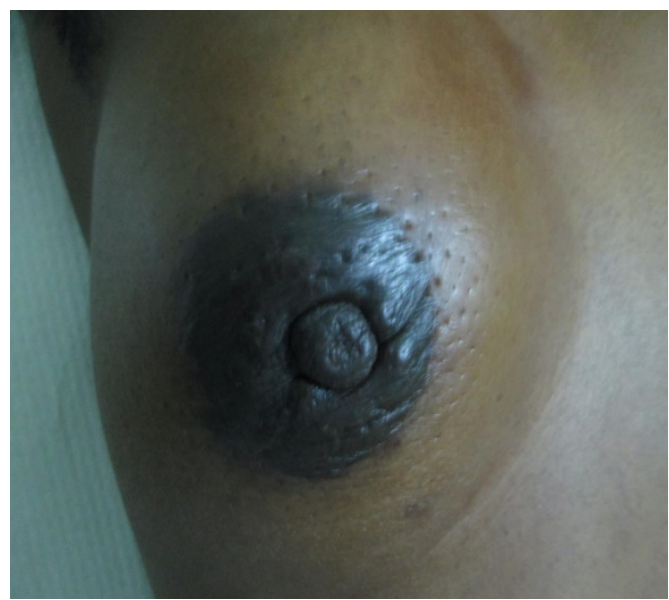

Figure 3. IBC with limited inflammatory signs.

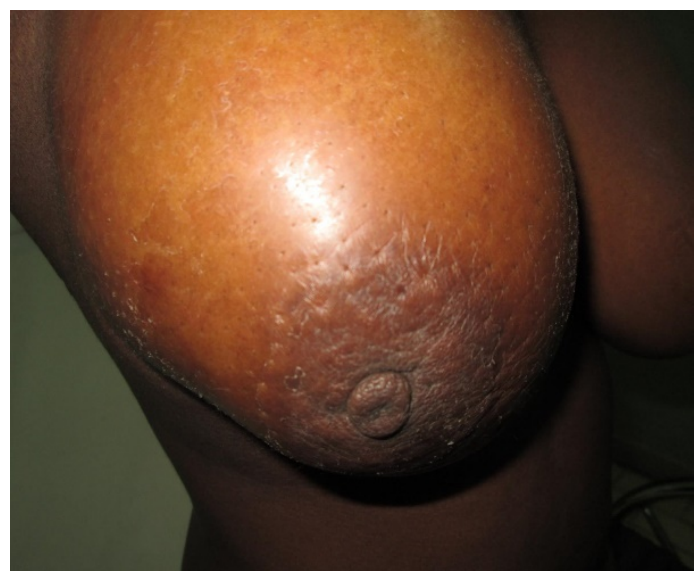

Figure 4. IBC with extensive inflammatory signs.

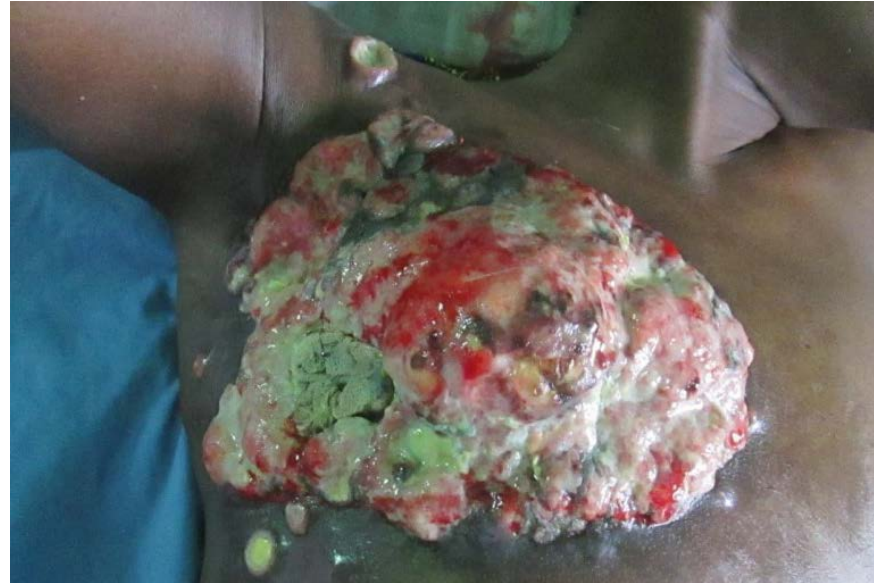

Figure 5. Breast cancer with skin lesions, making difficult to distinguish the IBC from locally advanced non inflammatory breast cancers.

\section{- Socio-demographic characteristics}

\section{o Age}

Age is a well-known risk factor for breast cancer: rare before the age of 35, 
its frequency increases with age, especially after 50 years. But concerning IBC, some authors report that it is more frequent in women under 50 [6] [12] [13] [14].

In this study the average age was 46.5 years and the majority of the patients (61.3\%) were actually less than 50 years old. Elsewhere in Africa, some authors have even reported series with a lower average age, close to 40 years [15] [16].

\section{o Socio-economic characteristics}

In our study the majority of patients had a low socioeconomic level: Low educational level (81.8\%), insufficient economic level (90.9\%). In Africa, several authors also found a high frequency of breast cancer in patients of low socioeconomic level [10] [11]. In many African countries there is no breast cancer screening program or social policy for the management of cancer which remains expensive. These two parameters are factors of delay in the consultation which could explain that some patients may neglect a noninflammatory initial tumor up to the appearance of inflammatory phenomenon.

\section{o History}

The usual risk factors of breast cancers are found in many of our patients: nulliparity (2.4\%), absence of breastfeeding (11.4\%), history of hormonal contraception (4.5\%), late menopause (18.18\%), first menstrual period before 12 years (52.3\%), family history of cancer (6.8\%).

In the literature, reported risk factors for IBC are common to those of all breast cancers [2] [17]. Nevertheless some authors reported that pregnancy and hispanic and black races are special risk factors for IBC [18] [19] [20].

\section{2) Clinical characteristics}

\section{- Consultation period}

Touré found that in our country about $80 \%$ of breast cancer patients consulted late due to lack of financial means, the use of traditional medication and diagnostic errors [10].

In our series, the average delay between the first signs and the first consultation was also long (10 months), and half of the patients waited more than 6 months before consulting. These long delays could alter the memory of patients on the exact start of their illness. Indeed these patients are usually of low education level, making unreliable the information about the exact duration of the disease progression and the chronology of the appearance of skin lesions.

\section{- Site of the tumor}

In this study, the IBC concerned the 2 breasts without significant difference: the right breast was affected in $52.3 \%$ and the left breast in $47.7 \%$. Several authors had made the same remarks and concluded that there is no preferential site for the IBC [21] [22] [23].

\section{- Clinical signs}

In our series, several patients had extensive inflammatory signs (38.6\%), lymph node involvement (84.1\%), and metastases (36.4\%). In the literature, the IBC are characterised by their rapid spread to lymph nodes and a high metastatic potential [2] [24] [25] [26] [28].

\section{3) Histological characteristic}




\section{- Histological type}

In our series, histology found that the majority of IBC were IDC (81.8\%) and had lymph embol (63.6\%). However, the IBC does not correspond to a specific histological entity, and all the usual types of invasive carcinoma of the breast (ductal, lobular, medullary, or small cell cancer) may be manifested in an inflammatory form [2].Regarding the lymphatic embols, their presence in the deep dermis or hypodermis confirms the inflammatory nature of this cancer but are found only in $2 / 3$ cases of the clinical diagnoses [2] [17].

\section{- Prognostic factors}

The majority IBC of our patients had as histoprognostic factors: an SBR III (54.5\%), a Ki 67 High (57.9\%), a negative hormone receptor, and a positive HER2 (68.4\%). These same observations were made by several authors in their studies [2] [27] [28] [29].

\section{4) Therapeutic characteristics}

In the study population, the majority of patients (56.8\%) has not benefited from a carcinologic treatment (surgery, radiotherapy, chemotherapy, hormonal therapy, targeted therapy) for 2 main reasons: either by medical indication-cons, or for lack of financial means to meet the prescribed care. In our country are the carcinologic treatments are expensive and are the responsibility of patients because there is no health coverage.

Moreover no patients received radiotherapy because it is unavailable in our country showing the limits of our technical equipment.

\section{5) Survival}

The survival at 5 years was low: it was $20 \%$ in the overall population, zero in untreated patients and $27 \%$ in patients who received carcinologic treatment.

The prognosis of IBC is daunting. In developed countries where radiotherapy is possible, the prognosis is better than in our countries but it is still reserved, with disease-free survival at 5 years less than $50 \%$, an overall survival at 5 years from $30 \%$ to $75 \%$ [2] [30].

\section{Conclusion}

This study allowed us to find that the IBC were relatively frequents in our country, especially affecting women of low socioeconomic level. The consultation delays were late and the management was limited by an incomplete technical equipment (no radiotherapy) darkening the prognosis. Therefore, in order to improve the prognosis, it is important to focus on the screening program practice in our country.

\section{Declarations}

Funding: None.

Conflict of interest: None.

\section{References}

[1] Sarrazin, D., Rouessé, J. and Arriagada, R. (1978) Les cancers du sein en poussée 
évolutive. La Revue Du Praticien, 28, 999-1006.

[2] Auclerc, G., Buthiau, D. And Brunet, A. (1999) Le cancer du sein inflammatoire. La Lettre du Sénologue, 3, 16-20.

[3] N'Koua-M'Bon, J.B., Bambara, A.T., Moukassa, D. and Gombé-Mbalawa, C. (2013) Clinical and Outcome Characteristics of Inflammatory Breast Cancers in Brazzaville. Bulletin du Cancer, 100, 147-153.

[4] Boussen, H., Bouzaiene, H., Ben Hassouna, J., Gamoudi, A., Benna, F. and Rahal, K. (2008) Inflammatory Breast Cancer in Tunisia: Reassessment of Incidence and Clinicopathological Features. Seminars in Oncology, 35, 17-24.

https://doi.org/10.1053/j.seminoncol.2007.11.017

[5] Levine, P.H. and Veneroso, C. (2008) The Epidemiology of Inflammatory Breast Cancer. Seminars in Oncology, 35, 11-16. https://doi.org/10.1053/j.seminoncol.2007.11.018

[6] Bouzbid, S. and Aouras, H. (2014) Le cancer du sein inflammatoire au centre hospitalouniversitaire d'Annaba, Algérie. Revue d'Epidémiologie et de Santé Publique, 62, 215-216.

[7] Woodward, W.A. and Cristofanilli, M. (2009) Inflammatory Breast Cancer. Seminars in Radiation Oncology, 19, 256-265.

https://doi.org/10.1016/j.semradonc.2009.05.008

[8] Walshe, J.M. and Swain, S.M. (2006) Clinical Aspects of Inflammatory Breast Cancer. Breast Disease, 22, 35-44. https://doi.org/10.3233/BD-2006-22105

[9] Rosa, M. (2010) Inflammatory Changes in Breast: How to Provide a Better Care to Our Patient. Archives of Gynecology and Obstetrics, 281, 901-905. https://doi.org/10.1007/s00404-009-1236-4

[10] Touré, M., Nguessan, E., Bambara, A.T., Kouassi, Y.K.K., Dia, J.M.L. and Adoubi, I. (2013) Factors Linked to Late Diagnosis in Breast Cancer in Sub-Saharan Africa: Case of Co^te d'Ivoire. Gynécologie Obstétrique et Fertilité, 41, 696-700.

[11] Meye, J.F., Ngomo-Klutsch, M. And Diallo, I. (2004) Cancer du sein au centre hospitalier de Libreville. Med Afr Noire, 8, 479-482.

[12] William, F., Anderson, A., Catherine, S., Bingshu, E. and Chen, A. (2005) Epidemiology of Inflammatory Breast Cancer (IBC). Breast Disease, 22, 9-23.

[13] Richards, M.A., Westcombe, A.M., Love, S.B., Littlejohns, P. and Ramirez, A.J. (1999) Influence of Delay on Survival in Patients with Breast Cancer: A Systematic Review. Lancet, 353, 1119-1126. https://doi.org/10.1016/S0140-6736(99)02143-1

[14] Hance, K.W., Anderson, W.F., Devesa, S.S., Young, H.A. and Levine, P.H. (2005) Trends in Inflammatory Breast Carcinoma Incidence and Survival: The Surveillance, Epidemiology and End Results Program at the National Cancer Institute. Journal of the National Cancer Institute, 97, 966-975. https://doi.org/10.1093/jnci/dji172

[15] Lo, A., Kleer, C., Banerjee, M., Omar, S., Khaled, H. and Eissa, S. (2008) Molecular Epidemiologic Features of Inflammatory Breast Cancer: A Comparison between Egyptian and US patients. Breast Cancer Research and Treatment, 112, 141-147. https://doi.org/10.1007/s10549-007-9833-Z

[16] Lo, A., Georgopoulos, A., Kleer, C., Banerjee, M., Omar, S. and Khaled, H. (2009) Analysis of RhoC Expression and Lympho Vascular Emboli in Inflammatory vs. Non-Inflammatory Breast Cancers in Egyptian Patients. Breast, 18, 55-59. https://doi.org/10.1016/j.breast.2008.11.002

[17] Lucas, F.V. and Perez-Messa, C. (1978) Inflammatory Carcinoma of the Breast. Cancer, 41, 1595-1599. 
[18] Lyman, G.H., Kuderer, N.M., Lyman, S.L., et al. (1997) Importance of Race on Breastcancer Survival. Annals of Surgical Oncology, 4, 80-87. https://doi.org/10.1007/BF02316814

[19] Amiri-Kordestani, L., Kamangar, F. and Zujewski, J.A. (2013) Inflammatory Breastcancer: Yetan Other Risk of the Obesity Epidemic? Journal of the National Cancer Institute, 105, 1340-1342. https://doi.org/10.1093/jnci/djt236

[20] Bonnier, P. (1997) Influence of Pregnancy on the Outcome of Breast Cancer: Acase-Control Study. International Journal of Cancer, 72, 720-727.

[21] Pasta, V., Mitri, F., Amabile, M.I. and Picardi, N. (2006) Inflammatory Breast Cancer. Annali Italiani di Chirurgia, 77, 275-279.

[22] Roshan, H. and Giordano, N. (2003) Inflammatory Breast Cancer: Clinical Progress and Themain Problems That Must Be Addressed. Breast Cancer Research, 5, 284-288. https://doi.org/10.1186/bcr608

[23] Florance, L., Ivane, B. and Lidereau, R. (2005) Update on Inflammatory Breast Cancer. Breast Cancer Research, 7, 52-58. https://doi.org/10.1186/bcr997

[24] Viens, P., Palangie, T., Janvier, M. and Fabbro, M. (1990) First Line High Dose Sequentialchemotherapy with rG-CSF and Repeated Blod Stem Cell Translantation in Untreated Inflammatory Breast Cancer. British Journal of Cancer, 81, 449-456. https://doi.org/10.1038/sj.bjc.6690714

[25] Lacour, J. and Hour, T. (1977) La place de la chirurgie dans le traitement des formesévolutives du cancer du sein. Méd Accord Chir, 19, 635-643.

[26] Brooks, H.L., Mandava, N., Pizzi, W. and Shah, S. (1998) Inflammatory Breast Carcinoma: A Community Hospital Experience. Journal of the American College of Surgeons, 186, 622-629. https://doi.org/10.1016/S1072-7515(98)00107-0

[27] Aziz, S.A., Khan, P.S., et al. (2001) Case Control Study of Prognostic Markers and Disease Outcome in Inflammatory Carcinoma Breast: A Unique Clinical Experience. The Breast Journal, 7, 398-404.

[28] Charafe-Jauffret, E., Mrad, K., Labidi, S.I., BenHamida, A., Ben Romdhane, K. and Ben Abdallah, M. (2007) Inflammatory Breast Cancers inTunisia and France Show Similar Immune Phenotypes. The Breast, 16, 352-358.

https://doi.org/10.1016/j.breast.2007.01.002

[29] Mourali, N., Nuenz, L. and Tabbane, F. (1980) Epidemiologic Features of Rapidly Progressing Breast Cancer inTunisia. Cancer, 46, 2741-2746.

[30] Jaiyesimi, I.A., Buzdar, A.U. and Hortobagyi, G. (1992) Inflammatory Breast Cancer: A Review. Journal of Clinical Oncology, 6, 1014-1024.

https://doi.org/10.1200/JCO.1992.10.6.1014 